\title{
Fuel Cell Electrodes Based on Carbon Nanotube/Metallic Nanoparticles Hybrids Formed on Porous Stainless Steel Pellets
}

\author{
S. M. Khantimerov, ${ }^{1,2}$ E. F. Kukovitsky, ${ }^{1}$ N. A. Sainov, ${ }^{1}$ and N. M. Suleimanov ${ }^{1,2}$ \\ ${ }^{1}$ Zavoisky Physical-Technical Institute of the Russian Academy of Sciences, Sibirsky Trakt 10/7, Kazan 420029, Russia \\ ${ }^{2}$ Kazan State Power Engineering University, Krasnoselskaya 51, Kazan 420066, Russia \\ Correspondence should be addressed to S. M. Khantimerov; khantim@mail.ru
}

Received 31 March 2013; Revised 5 August 2013; Accepted 7 August 2013

Academic Editor: Dmitry Murzin

Copyright (c) 2013 S. M. Khantimerov et al. This is an open access article distributed under the Creative Commons Attribution License, which permits unrestricted use, distribution, and reproduction in any medium, provided the original work is properly cited.

\begin{abstract}
The preparation of carbon nanotube/metallic particle hybrids using pressed porous stainless steel pellets as a substrate is described. The catalytic growth of carbon nanotubes was carried out by CVD on a nickel catalyst obtained by impregnation of pellets with a highly dispersive colloidal solution of nickel acetate tetrahydrate in ethanol. Granular polyethylene was used as the carbon source. Metallic particles were deposited by thermal evaporation of Pt and Ag using pellets with grown carbon nanotubes as a base. The use of such composites as fuel cell electrodes is discussed.
\end{abstract}

\section{Introduction}

Fuel cells are electrochemical sources of current in which the chemical energy of the fuel is directly transformed to the electrical energy through the redox chemical reactions proceeding at catalytic electrodes $[1,2]$. The good properties of the catalyst support, such as high surface area, low resistance, and high mechanical strength and chemical stability, are essential for catalytic electrodes. The use of carbon nanotubes (CNTs) as a support for catalytic materials is the promising method to prepare novel high efficient electrodes for fuel cells [3-5]. The surface area of carbon nanotubes varies from $500 \mathrm{~m}^{2}$ per gram for the multiwall nanotubes to $1500 \mathrm{~m}^{2}$ per gram for the single wall nanotubes. Chemical vapor deposition (CVD) is one of the methods by which the carbon nanotubes can be obtained [6-8]. 3dgroup metal particles $(\mathrm{Fe}, \mathrm{Co}$, and $\mathrm{Ni}$ ) deposited on different substrates are usually used as catalysts for CNTs growth. Due to their low cost, high strength, and corrosion resistance, stainless steels are considered to be good candidates as substrates used in polymer electrolyte membrane (PEM) fuel cell [9]. Traditionally, a single PEM fuel cell consists of few major components: membrane, catalyst, catalyst support, catalyst layer, gas diffusion layer, and current collector.
In this paper, experiments on carbon nanotube growth on porous pellets prepared from stainless steel powders and direct deposition of catalytic metallic particles of $\mathrm{Pt}$ and $\mathrm{Ag}$ on carbon nanotubes obtained at given substrates are presented.

The advantage of this approach implies that after CNTs' growth on porous pellets followed by carbon nanotubes decoration by catalytic nanoparticles, this hybrid structure represents the fuel cell material in which three functions are combined: catalytic electrode, gas diffusion layer, and current collector.

\section{Materials and Methods}

The pellets were pressed from commercially available stainless steel (russian type X23H18) powders. The pellets obtained were disks with a diameter of $10 \mathrm{~mm}$ and thickness of $2 \mathrm{~mm}$. One of the pellet's sides was impregnated with highly dispersive colloidal solution of nickel acetate in ethanol. For this purpose, $0.236 \mathrm{~g}$ of chemically pure $\mathrm{Ni}$ acetate tetrahydrate $\left(\mathrm{Ni}(\mathrm{ac})_{2} \cdot 4 \mathrm{H}_{2} \mathrm{O}\right)$ was dissolved in $5 \mathrm{~mL}$ of ethanol on heating up to boiling temperature. Then the solution was allowed to air cool to room temperature. The porous stainless steel pellets were impregnated with the transparent solution by 
deposition of 3-5 drops on one side of the pellets. After air drying, gel-like material was formed in pores and on the pellet surface. Such pellets were used as substrates with deposited catalyst for carbon nanotube growth in a CVD process of 15 min duration. The gel was decomposed and reduced to nickel nanoparticles under heating at an early stage of CVD process providing fast nanotube growth. The synthesis of carbon nanotubes was carried out at $800^{\circ} \mathrm{C}$ using granular polyethylene as the source of carbon [10]. The need for catalyst deposition using stainless steel pellet's impregnation with $\mathrm{Ni}(\mathrm{ac})_{2}$ /ethanol solution was caused by the following. It was not possible to obtain nanotube carbon immediately on stainless steel during the CVD process. This was due to the low process duration. Surface layers of stainless steel had no time to fragment into catalytically active metal nanoparticles. At the same time, short reaction duration prevented steel pellets from destruction and they held an initial shape and pore structure.

Morphology of the samples obtained was investigated by optical and transmission electron microscopy (Tesla BS500). The metallic Pt and Ag nanoparticles were deposited by means of thermal evaporation in a vacuum.

\section{Results and Discussion}

3.1. Transmission Electron Microscopy. Figure 1 shows the transmission electron microscopy (TEM) image of the CNT/ metallic particles hybrid formed at porous stainless steel pressed pellet.

From the analysis of optical and electron microscopy measurements, it is found that the formation of carbon nanotubes takes place both on the surface of the pellet and inside of pores of the subsurface layer (Figure 2).

Carbon nanotubes had an arbitrary orientation and were intertwisted to one another forming thin "felt" mat on the surface of the pellet.

As it was already mentioned, catalytic particles of $\mathrm{Pt}$ and $\mathrm{Ag}$ were produced by thermal evaporation in a vacuum. As one can see from Figure 1, it gives pretty thick metallic agglomerations (black flakes on the figure) for both the Pt and $\mathrm{Ag}$ and no well-defined nanoparticles of these metals were observed. The following interesting fact was established in the course of experiments. During TEM measurements, the evaporation of Pt and Ag deposited on CNT layer takes place due to the effect of the electron beam. As a result, the formation of precipitated metallic particles at the surface of carbon nanotubes was observed but it was already in the form of nanoparticles. It may be suggested that for the large metallic particles the energy that is absorbed during the irradiation by electron beam is not dissipated for that time. Owing to this, heating of metallic nanoparticles occurs and, as a result, their evaporation takes place. A similar effect was observed under transmission electron microscopy measurements of carbon nanotubes with deposited $\mathrm{Ni}$ nanoparticles with dimensions of about $50 \mathrm{~nm}$. As one can see from Figure 3(b), the holes of nanometer scale in the place of nanoparticles localization on the CNTs' walls are arising (Figure 3(a) shows initial carbon nanotubes with deposited Ni nanoparticles).

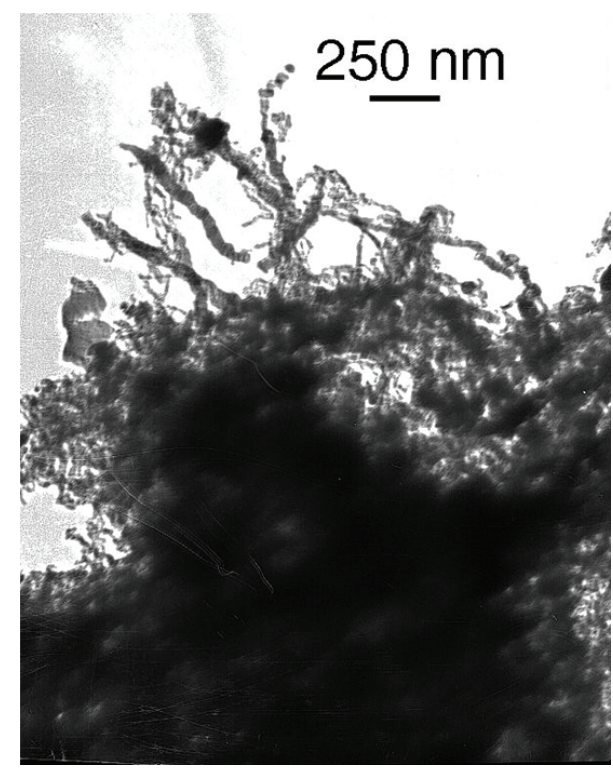

FIGURE 1: TEM image of carbon nanotube/metallic particles hybrids obtained on the pressed stainless steel pellets. Typical metallic particle agglomerations (black flakes) were observed for both Pt and Ag.

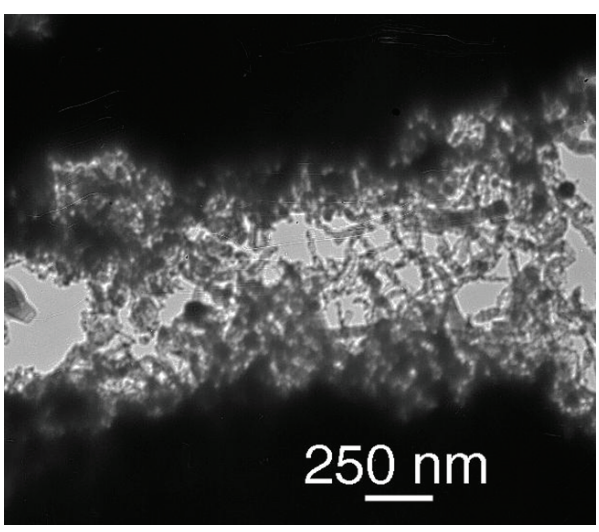

FIGURE 2: TEM image of carbon nanotube/metallic particles hybrids inside of pressed stainless steel pellets. As an example, metallic particles agglomerations of $\mathrm{Pt}$ (black flakes) with a few nanoparticles (black circles) are presented.

The formation of the holes can be understood by the following way. Under electron irradiation, both the effect of heating of Ni nanoparticles and dissolving of carbon in the particles take place. At high temperature, the metallic particles evaporate together with dissolved carbon creating the hole in carbon nanotube wall.

3.2. Testing of the Electrodes within the Fuel Cell. A model of the hydrogen-oxygen fuel cell has been developed in order to measure in situ electrical characteristics of porous nanocomposite carbon-metal electrodes (Figure 4). The laboratory model consisted of two symmetrical parts. Each part had a mounting seat where a disc-like anode and cathode were placed. These disk electrodes are constituted from carbon nanotubes with metal nanoparticles based on porous stainless 


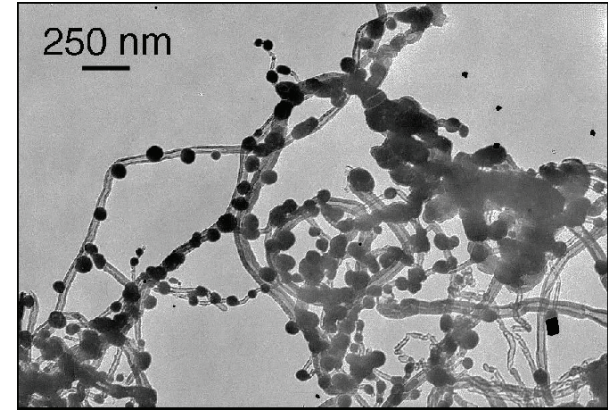

(a)

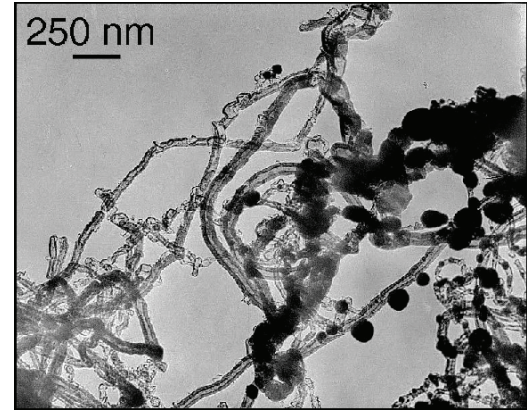

(b)

FIGURE 3: TEM image of unsupported carbon nanotubes with (a) deposited Ni nanoparticles and (b) through holes of nanometer scale on walls of carbon nanotubes.

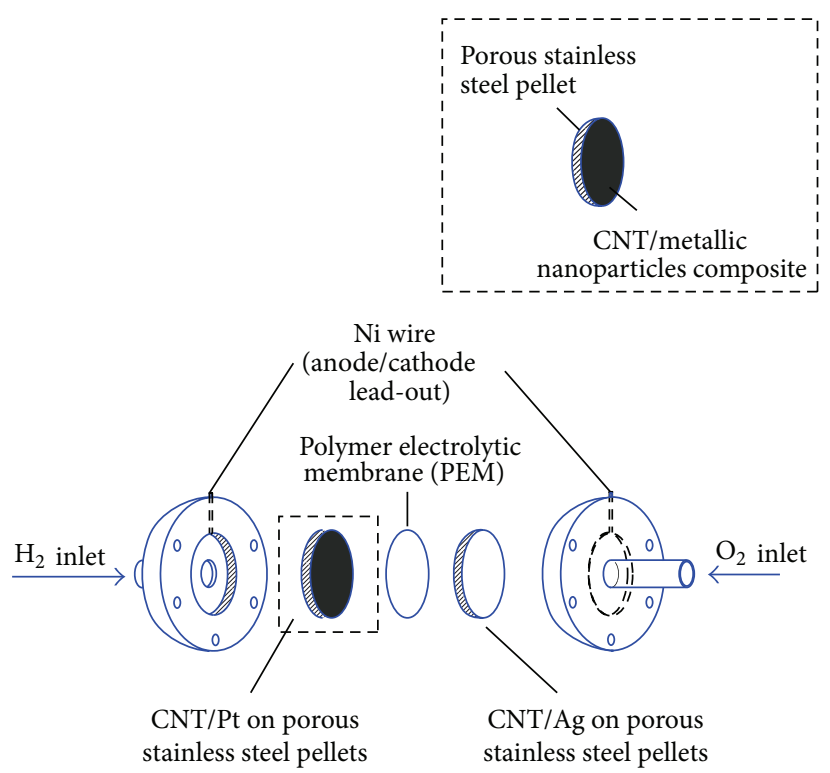

FIGURE 4: Laboratory model of hydrogen-oxygen fuel cell.

steel. The electrodes used had the following parameters: diameter: $10 \mathrm{~mm}$, thickness: $2 \mathrm{~mm}$, and $\mathrm{Pt}$ (for anode) and $\mathrm{Ag}$ (for cathode) loading: $0.75 \pm 0.1 \mathrm{mg} / \mathrm{cm}^{2}$. After placing of the polymer electrolyte membrane (PEM) (Nafion 115, Aldrich) between the electrodes, two halves of the fuel cell were fastened together with bolts. Hydrogen and oxygen gas were fed through channels to the porous anode and cathode electrodes, respectively.

It was found that both hydrogen and oxygen penetrated through porous electrodes when applying an excess pressure (0.15 bar).

The results of electrical characteristics measuring of the experimental fuel cell on the basis of the electrodes developed and are shown in Figure 5.

Open circuit voltage of the fuel cell was $0.94 \mathrm{~V}$, the shape of the current-voltage characteristic was almost linear (Figure 5, curve 1). The results showed the maximum power density of $147 \mathrm{~mW} / \mathrm{cm}^{2}$ (Figure 5, curve 2). The given results do not exceed those obtained by other authors or obtained

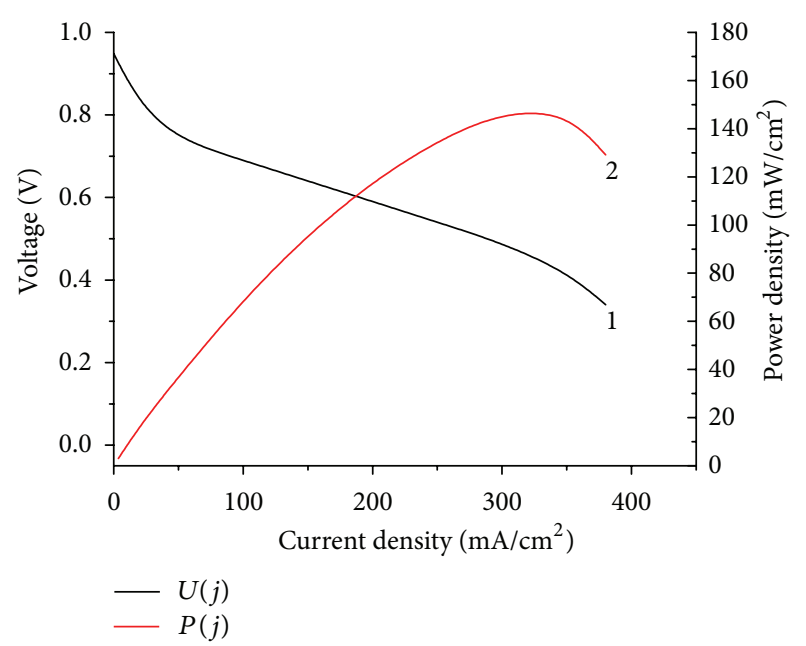

FIGURE 5: Electrical characteristics of the fuel cell based on carbon nanotube/metallic particle hybrids formed on porous stainless steel pellets as electrodes. $1 U(j) ; 2 P(j)$. 
for commercial electrodes $[11,12]$. However, the developed electrodes can simplify the design of fuel cells.

\section{Conclusions}

Preparation of $\mathrm{CNT} /$ metallic particles hybrids on pressed porous stainless steel pellets was carried out. Carbon nanotubes were grown by CVD on a nickel catalyst obtained by impregnation of pellets with highly dispersive colloidal solution of nickel acetate in ethanol followed by heat treatment. The effect of redeposition of metallic agglomerations and burning out of holes in carbon nanotube walls under microscope electron beam was observed.

The use of such composites in fuel cell technology can simplify the fuel cell design since, in this hybrid structure catalytic electrode, gas diffusion layer and current collector are combined.

\section{Acknowledgment}

This work was partially supported by the Russian Foundation for Basic Research (Grant no 12-08-00755-a).

\section{References}

[1] G. J. Offer, "PEM fuel cell electrocatalysts and catalyst layers: Fundamentals and applications," Platinum Metals Review, vol. 53, no. 4, pp. 219-220, 2009.

[2] P. Costamagna and S. Srinivasan, "Quantum jumps in the PEMFC science and technology from the 1960s to the year 2000: Part II. Engineering, technology development and application aspects," Journal of Power Sources, vol. 102, no. 1-2, pp. 253-269, 2001.

[3] Y. Wang, K. S. Chen, J. Mishler, S. C. Cho, and X. C. Adroher, "A review of polymer electrolyte membrane fuel cells: technology, applications, and needs on fundamental research," Applied Energy, vol. 88, no. 4, pp. 981-1007, 2011.

[4] U. Heiz and E. L. Bullock, "Fundamental aspects of catalysis on supported metal clusters," Journal of Materials Chemistry, vol. 14, no. 4, pp. 564-577, 2004.

[5] T. Matsumoto, T. Komatsu, H. Nakano et al., "Efficient usage of highly dispersed Pt on carbon nanotubes for electrode catalysts of polymer electrolyte fuel cells," Catalysis Today, vol. 90, no. 34, pp. 277-281, 2004.

[6] S. Maruyama, R. Kojima, Y. Miyauchi, S. Chiashi, and M. Kohno, "Low-temperature synthesis of high-purity single-walled carbon nanotubes from alcohol," Chemical Physics Letters, vol. 360, no. 3-4, pp. 229-234, 2002.

[7] R. Brukh and S. Mitra, "Mechanism of carbon nanotube growth by CVD," Chemical Physics Letters, vol. 424, no. 1-3, pp. 126-132, 2006.

[8] B. Zheng, Y. Li, and J. Liu, "CVD synthesis and purification of single-walled carbon nanotubes on aerogel-supported catalyst," Applied Physics A, vol. 74, no. 3, pp. 345-348, 2002.

[9] H. Wang, M. A. Sweikart, and J. A. Turner, "Stainless steel as bipolar plate material for polymer electrolyte membrane fuel cells," Journal of Power Sources, vol. 115, no. 2, pp. 243-251, 2003.

[10] E. F. Kukovitsky, S. G. L'vov, N. A. Sainov, and V. A. Shustov, "CVD growth of carbon nanotube films on nickel substrates," Applied Surface Science, vol. 215, no. 1-4, pp. 201-208, 2003.
[11] Y.-G. Chun, C.-S. Kim, D.-H. Peck, and D.-R. Shin, "Performance of a polymer electrolyte membrane fuel cell with thin film catalyst electrodes," Journal of Power Sources, vol. 71, no. 1-2, pp. 174-178, 1998.

[12] V. Mehta and J. S. Cooper, "Review and analysis of PEM fuel cell design and manufacturing," Journal of Power Sources, vol. 114, no. 1, pp. 32-53, 2003. 

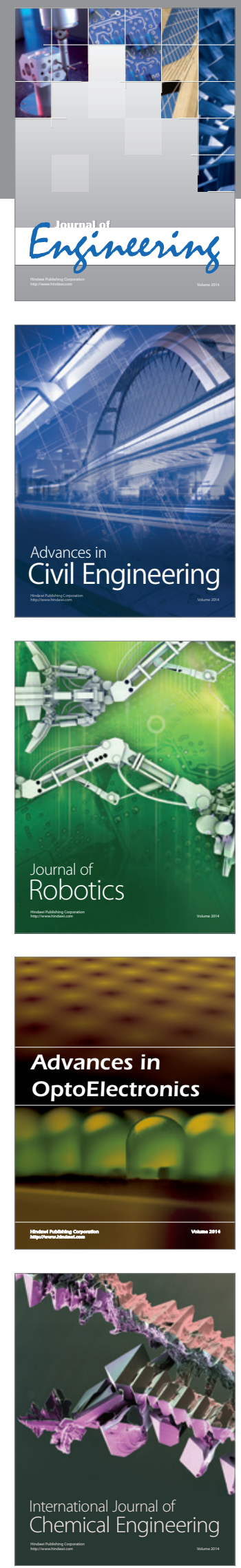

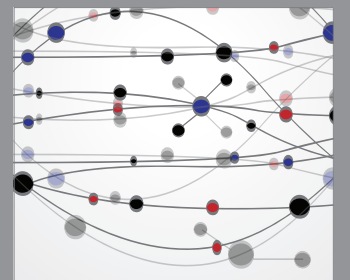

The Scientific World Journal
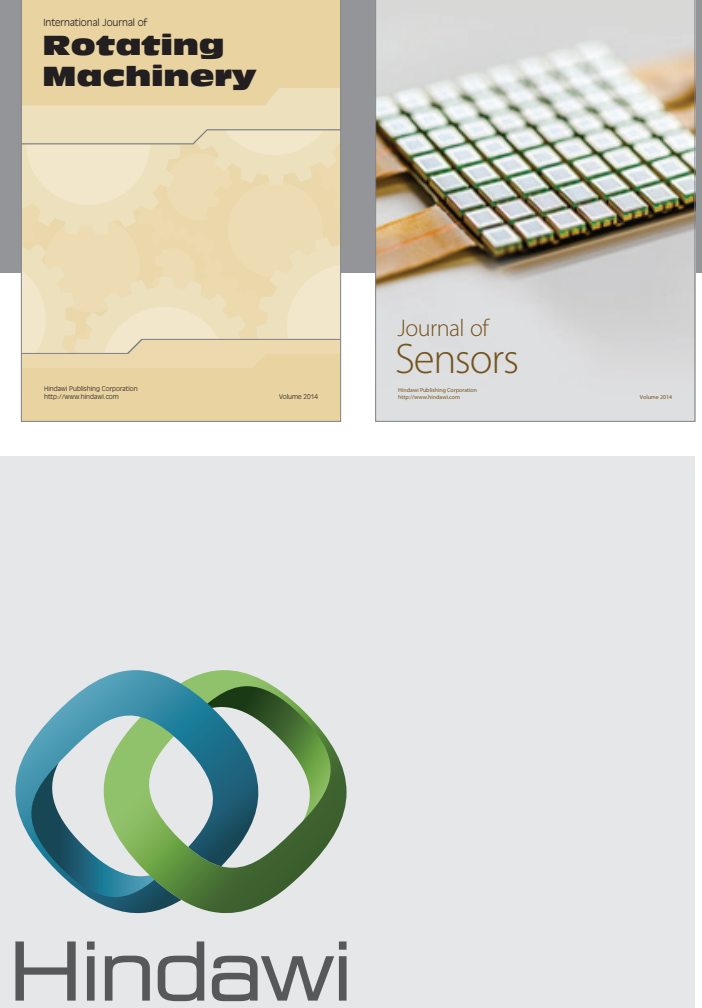

Submit your manuscripts at http://www.hindawi.com
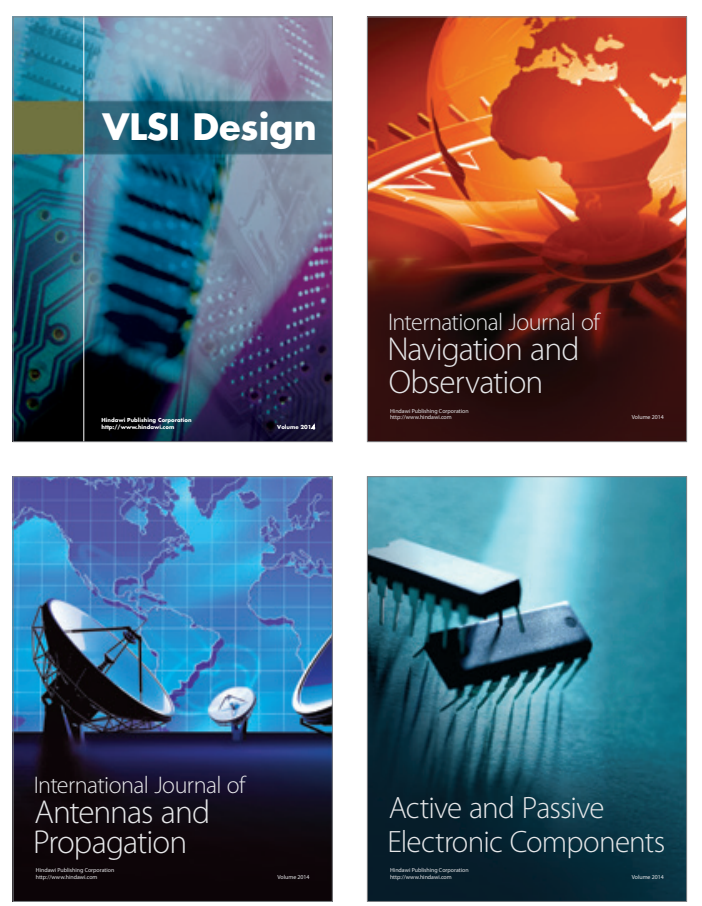
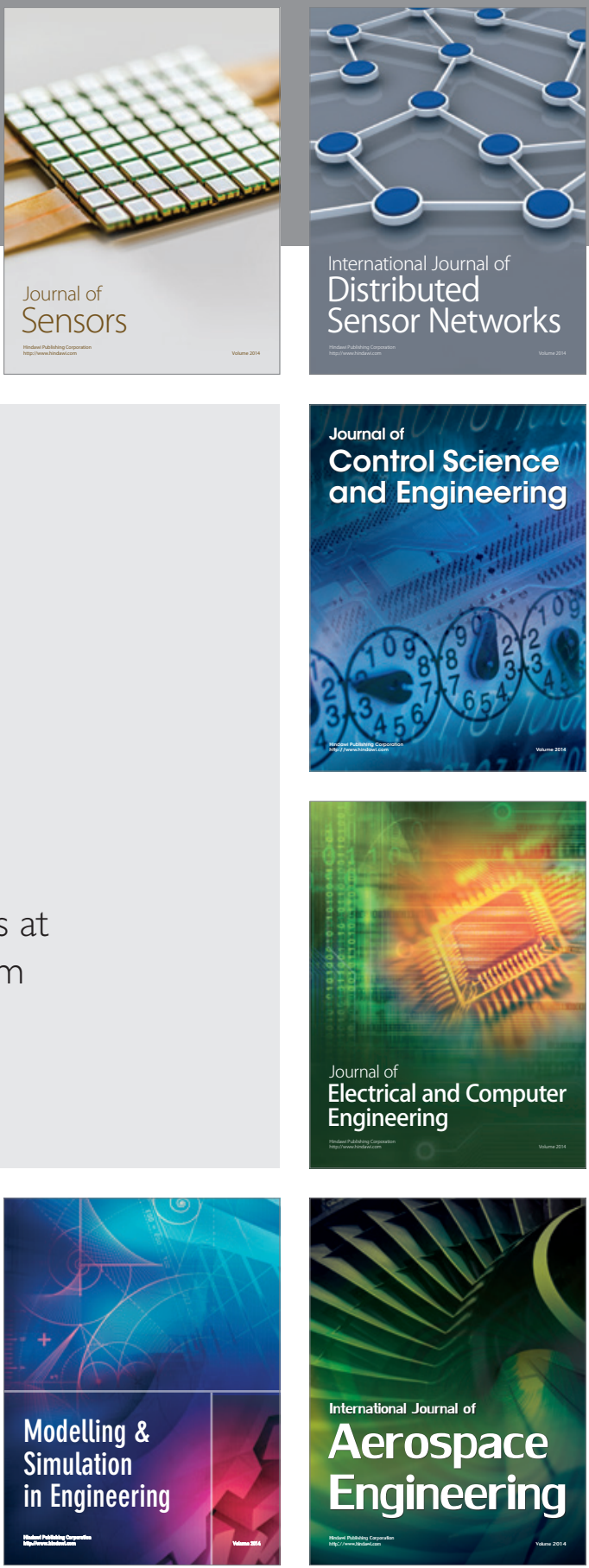

Journal of

Control Science

and Engineering
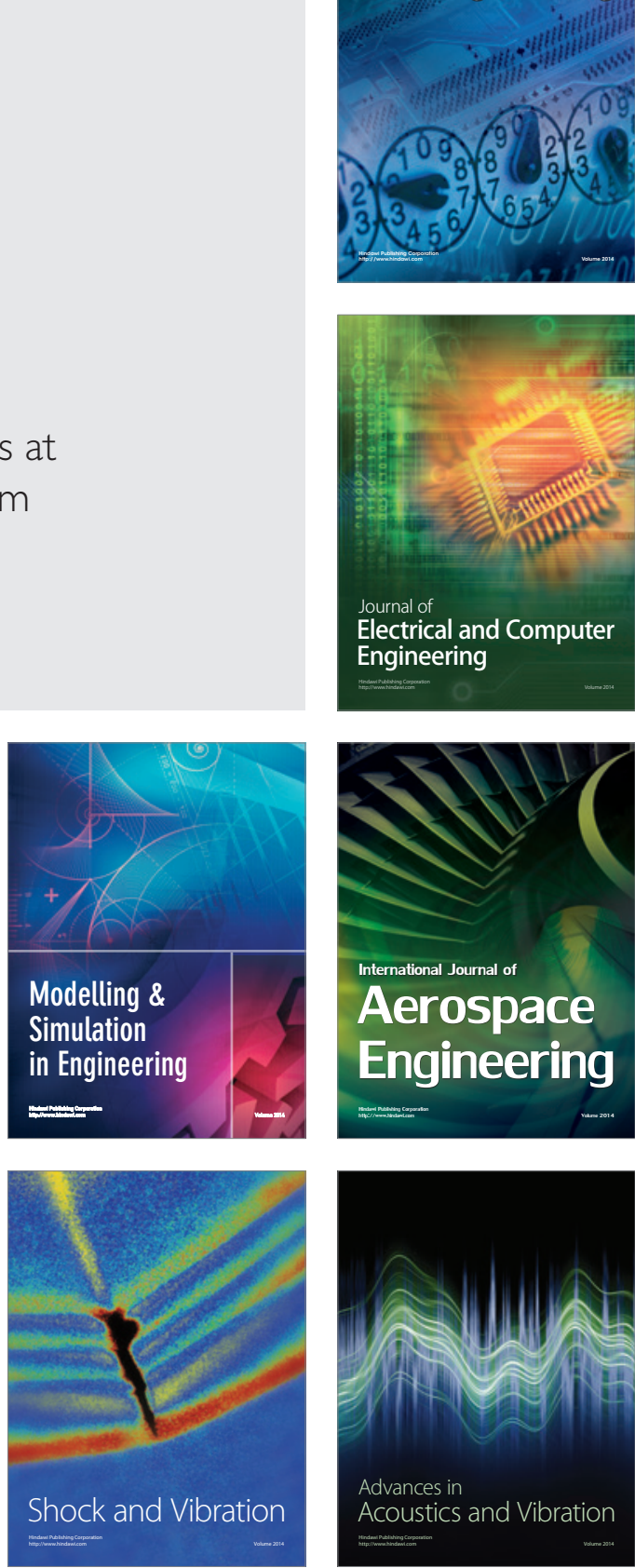